\title{
Práticas de mediação na pesquisa epidemiológica sob o ponto de vista etnográfico
}

\section{Mediation practices in epidemiological research from an ethnographic perspective}

\author{
Luís Augusto Vasconcelos da Silva \\ Professor adjunto da Universidade Federal do \\ Vale do São Francisco \\ Av. Presidente Tancredo Neves, 100 \\ 56306-410 - Petrolina - PE - Brasil \\ luis.silva@univasf.edu.br
}

Recebido para publicação em abril de 2007. Aprovado para publicação em agosto de 2008.
SILVA, Luís Augusto Vasconcelos da. Práticas de mediação na pesquisa epidemiológica sob o ponto de vista etnográfico. História, Ciências, SaúdeManguinhos, Rio de Janeiro, v.16, n.1, jan.-mar. 2009, p.109-128.

Resumo

Durante 1998 acompanhei uma rede de comunicação cultural na produção de dados epidemiológicos, com uma abordagem etnográfica em estudos da ciência. Inserido nas atividades diárias de um grupo de pesquisa em epidemiologia, registrei alguns aspectos do processo de produção científica, como as estratégias e as negociações envolvidas na manutenção e circulação dos dados produzidos. Este trabalho descreve a trajetória de investigação epidemiológica e a rede de interação de seus atores, incluindo a participação de técnicos no processo de negociação das práticas científicas. Além de destacar atividade contínua de negociação e transformação de dados e informação epidemiológica, problematizo a separação de ciência e política ou de natureza e cultura/sociedade, e enfatizo a participação coletiva no processo de produção científica.

Palavras-chave: antropologia da ciência; epidemiologia; práticas científicas; atividade de mediação.

\section{Abstract}

During 1998 I accompanied a cultural communication network in the production of epidemiological data, which used an ethnographic approach to studies of science. Inserted in the daily activities of an epidemiological research group, I registered some aspects of the scientific production process, such as the strategies and negotiations involved in the maintenance and circulation of the data produced. This paper describes the trajectory of epidemiological research and the interaction network of its actors, including the participation of technicians in the negotiation of the scientific practices. In addition to highlighting the continuous activity of negotiation and transformation of epidemiological data and information, I analyze the separation of science and politics or of nature and culture-society, and emphasize the collective participation in the process of scientific production.

Keywords: anthropology of science; epidemiology; scientific practices; mediation activity. 


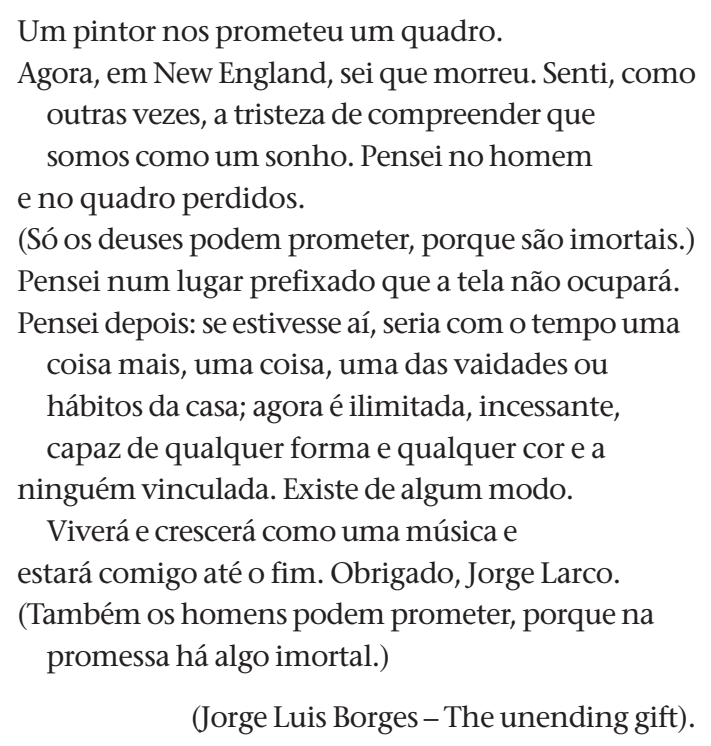

$\mathrm{H}$ á ao menos uma analogia possível entre a leitura do texto "The unending gift", de Jorge Luis Borges, e a construção de textos científicos: no processo de produção científica, somos nós, humanos, que construímos os argumentos - descrições e explicações - fazendo-os circularem sob a forma de textos. Todavia, em relação à possibilidade infinita de interpretação e geração de textos - ou promessas científicas, parafraseando Borges -, há algumas ressalvas a fazer: primeiro, os textos devem ser traduzidos em gramática comum de significação; segundo, eles possibilitam novas respostas ou futuras promessas, ao mesmo tempo em que uma comunidade de leitores específicos reduz e libera essas mesmas possibilidades interpretativas; terceiro, no cotidiano de transformação de textos, ocorre um engajamento coletivo que não se reduz às fronteiras prescritas pela comunidade científica, incluindo as agências de financiamento, os diversos grupos de interesse (ecológicos, econômicos, políticos, comunitários etc.) e os demais atores não-humanos que participam, ativamente, como mediadores do processo de produção científica.

Com o objetivo de focalizar alguns desses nós do cotidiano de práticas científicas, apresento descrição etnográfica da produção de dados epidemiológicos ${ }^{1}$, principalmente a partir do engajamento de técnicos - entrevistadoras de campo - responsáveis por parcela significativa da coleta de dados. Este artigo representa, pois, tentativa de construir ou viabilizar uma reflexão sobre a autoria plural, polifônica, de textos científicos e, por extensão, de meu próprio texto etnográfico (Clifford, 1998). Nessa perspectiva, serão apresentados alguns rabiscos, improvisações, não-ditos e momentos importantes que compõem atividades de pesquisa, geralmente deixados no esquecimento.

Focalizo, portanto, o discurso científico-epidemiológico como prática social, com usos e linguagens específicos, permeada por uma diversidade cultural, culturas de conhecimento (Knorr-Cetina, 1999), no sentido de abertura aos diferentes contextos de saberes e práticas. Na mesma direção de Latour e Woolgar (1997), descrevo a dinâmica cotidiana de alguns atores envolvidos na rede de produção de dados epidemiológicos. 
Esses autores propõem reconhecer o 'fenômeno científico' em seu próprio local de transformação, a partir das muitas operações sobre os enunciados e inscrições (gráficos, tabelas, imagens, traços etc.). Uma vez que se disponha do produto final (fatos), as etapas intermediárias que viabilizaram essa produção vão sendo esquecidas, e assim os procedimentos materiais vão sendo relegados à pura técnica. A natureza, então, entra em ação como 'suplemento' que cessa um debate (Latour, 2000, p.162).

Latour (1994, 1999a), entretanto, busca não reduzir a produção científica ao pólo da sociedade nem ao da natureza, mas fazer justiça às trajetórias de entidades estudadas, podendo ocupar muitas posições; em outras palavras, "as essências tornam-se existências e então essências novamente" (Latour, 1999a, p.286). Nessa perspectiva, a teoria ator-rede (Law, 1992; Latour, 1996, 1999a; Callon, 1999) significa mudança de topologia, ou "mudança de metáforas para descrever essências" (Latour, 1996, p.370). Em vez de superfícies ou esferas, pode-se pensar em termos de nós, com tantas dimensões quantas conexões existirem.

A retórica e a construção de textos científicos não ocorrem no vazio, separadamente, sem a co-produção ou mediação de atores heterogêneos (humanos e não humanos), ou seja, sem a participação conjunta, interativa, de máquinas, objetos, cientistas, microorganismos etc., constituindo-se mutuamente. Segundo a teoria ator-rede, todos os agentes que participam do processo de produção científica são considerados produtos ou efeitos gerados em uma rede ordenada de materiais heterogêneos, cujas resistências foram superadas (Law, 1992). De forma mais simétrica, utiliza-se, então, a noção de ator para fazer referência a qualquer coisa que tenha impacto ou afete outra, produzindo diferença: "tudo que for capaz de produzir uma diferença em uma rede será considerado como um ator, e todo ator definirá a si mesmo pela diferença que ele produz" (Lévy, 2004, p.137). Nessa trajetória de múltiplas ações, de efeitos interativos (Law, 1992), os humanos, com seus padrões e jogos de linguagem, são afetados ou produzidos pela circulação - e emergência - de máquinas e artefatos, também investidos de historicidade (Latour, 1994).

O reconhecimento de práticas científicas específicas e de variabilidade de culturas epistêmicas (Knorr-Cetina, 1999) favoreceu essa minha trajetória etnográfica, com o objetivo de assimilar uma rotina de transformação de signos, repertórios e estratégias de construção de dados e informação científica, um esforço conjunto de superação das resistências de atores diversos. Destaco que distintos atores (não-cientistas) puderam ser localizados, permitindo que os enunciados fossem articulados e confrontados nessa arena transepistêmica (Knorr-Cetina, 1983). No decorrer desse processo, diferentes critérios de decisão, não restritos à comunidade científica, estavam implicados, bem como diversos contextos e contingências da prática epidemiológica.

Conforme será destacado, o reconhecimento de uma rede interativa, de múltiplas participações e posicionamentos, principalmente com a presença de técnicos (entrevistadoras de campo), viabilizou a compreensão dos vários sentidos que os textos podem adquirir no fluxo ou movimento de construção de dados e informação científica. Os diversos encontros dialógicos ou fluxo comunicacional entre técnicos, informantes, pesquisadores, tecnologias e outros atores não humanos que co-participavam, diariamente, da produção de dados epidemiológicos, compõem essa minha experiência etnográfica. 


\section{A (re)construção de uma trajetória etnográfica}

Esta narrativa refere-se a um grupo de pesquisa epidemiológica do Instituto de Saúde Coletiva da Universidade Federal da Bahia (UFBA), responsável por dois importantes projetos de pesquisa em 1998: Avaliação da Eficácia do Uso da Segunda Dose de BCG na Idade Escolar - Projeto BCG e Avaliação do Impacto sobre a Saúde do Programa de Saneamento Ambiental de Salvador e Cidades do Entorno da Baía de Todos os Santos - Projeto Bahia Azul. Neste artigo, será focalizado apenas o projeto Bahia Azul, destacando, principalmente, a participação conjunta de técnicos e entrevistadoras de campo na produção de dados epidemiológicos.

Ao inserir-me no projeto Bahia Azul, encontrei referidos em seus documentos os seguintes objetivos gerais: (a) avaliar o impacto das medidas de saneamento, resultantes do programa, sobre os níveis de saúde da população que habita as áreas de influência das bacias de Salvador e o entorno da Baía de Todos os Santos; (b) transferir as tecnologias de avaliação para grupos técnicos dos órgãos governamentais; (c) suprir os programas de educação ambiental com informações técnico-científicas apropriadas.

Dentre as diversas atividades prescritas, destacava-se a coleta de dados nas áreas incluídas no programa de saneamento ambiental mediante: amostras de fezes; aplicação de questionários sobre condições de vida, condições sociais e morbidade referida; medição antropométrica; amostras de sangue para medida de hemoglobina e inquéritos malocológicos dos hospedeiros intermediários do Schistossoma mansoni.

Durante o período de minha participação, vários atores foram acompanhados nos diferentes contextos de investigação. Por meio de aproximação que teve início nas localidades do próprio Instituto de Saúde Coletiva da UFBA, nos respectivos espaços físicos em que estavam alocados os técnicos e coordenadores do projeto Bahia Azul, pude identificar importantes momentos e fases das atividades de pesquisa focalizadas. A interlocução contínua com alguns coordenadores-técnicos envolvidos nas diversas atividades de pesquisa foi imprescindível para consolidação de meu vínculo com outros mediadores importantes da prática de pesquisa epidemiológica.

Quando iniciei minha própria atividade de pesquisa, o projeto Bahia Azul distribuía suas atividades em subprogramas. Minha inserção ocorreu, basicamente, no subprograma responsável pela avaliação do impacto sobre algumas infecções e as deficiências nutricionais na população infantil (de zero a três anos), sendo possível localizar e acompanhar seus atores-pesquisadores nos contextos de coleta e análise de dados, principalmente as entrevistadoras de campo e a equipe responsável por pesar e medir as crianças.

O cotidiano do projeto Bahia Azul mobilizava a participação de estudantes, bolsistas de iniciação científica, alunos de pós-graduação, profissionais, técnicos e pesquisadores, oriundos de diferentes áreas e transitando em diferentes subprogramas de pesquisa. Esse coletivo viabilizava a circulação contínua de dados e informações atendendo às demandas dos investidores e financiadores da pesquisa, mais precisamente o governo da Bahia, que havia solicitado o projeto de avaliação. No decorrer desse meu percurso, cada momento ou fase da pesquisa acompanhada pôde constituir narrativas referentes ao processo de saúdedoença-cuidado, ainda que todos os momentos particularizados estivessem direcionados para a construção geral de repertórios componentes de discurso científico/epidemiológico, 
levando-se em consideração todo um 'contexto comunicativo' de hábitos, leis e acordos que orientam o processo de interpretação (Eco, 1999, p.288), assim como as próprias diferenças e tradições disciplinares dos atores-pesquisadores que formavam os subprogramas de pesquisa, como epidemiologistas, nutricionistas, geógrafos, estatísticos, cientistas sociais etc.

Como mediadoras do processo de produção e circulação de dados epidemiológicos, as entrevistadoras de campo (todas mulheres, com segundo grau completo), na atividade cotidiana de investigação científica, encontravam-se engajadas em momentos dialógicos importantes para a produção de dados e informação científica. Responsáveis, de certa forma, pela manutenção e circulação dos dados referentes à incidência de diarréia em crianças de zero a três anos, as entrevistadoras colaboravam para a manutenção da própria coorte, uma vez que estabeleciam diálogo de confiança com as informantes ou abertura na comunicação entre população (mães/crianças/comunidade) e pesquisa.

Ao todo, acompanhei seis entrevistadoras em minhas visitas de campo, que ocorreram em período posterior à observação de suas reuniões semanais no Instituto de Saúde Coletiva da UFBA, quando apresentavam as fichas de seguimento e de avaliação (instrumento de pesquisa) e eram orientadas por suas supervisoras. Periodicamente, a própria supervisora acompanhava a entrevistadora em campo, cumprindo um roteiro de análise sobre o andamento das atividades. Cada supervisora era responsável por um grupo de entrevistadoras, distribuídas nas distintas áreas do projeto (segundo a distribuição censitária do Instituto Brasileiro de Geografia e Estatística - IBGE), desenvolvendo atividade de mediação entre pesquisador ou coordenador de pesquisa e entrevistadoras de campo.

O acompanhamento focal de alguns atores-pesquisadores representou oportunidade ímpar para conhecer e compartilhar a rotina de trabalho. Na verdade, o acompanhamento focal, como forma de observação participante da rotina de alguns mediadores de pesquisa, pôde viabilizar minha inserção na arena transepistêmica (Knorr-Cetina, 1983) do projeto Bahia Azul, possibilitando conhecer diferentes contextos e contingências da prática de produção epidemiológica. A partir de minhas notas e diário de campo, pude descrever a rede de produção científica, levando em consideração minha própria posição de intérprete em relação aos dados produzidos.

Diferente da experiência de Latour e Woolgar (1997), algumas entrevistas abertas, individuais e em grupo, foram realizadas com diversos membros do projeto Bahia Azul, muitos deles com repertórios diferenciados quanto à prática científica, buscando-se comparar melhor os discursos dos cientistas e demais atores-pesquisadores com minhas próprias interpretações e descrições de campo. Mulkay, Potter e Yearley (1983), referindo-se aos discursos científicos como uma cultura constitutiva de práticas discursivas, através de registros lingüísticos coexistentes e assimétricos (formais/empíricos e contingentes), chamam a atenção para a análise discursiva quando se propõe compreender como estes discursos são sistematicamente organizados. Os diferentes repertórios ${ }^{2}$ implicados no uso da linguagem científica (localizada contextualmente) permitem, segundo os autores, elucidar como as operações da linguagem usual dos cientistas produzem um mundo social multifacetado.

Hoje, buscando retomar um discurso fixado na escrita (Geertz, 1989; Ricouer, 1996), voltando no tempo e reconhecendo alguns desses significados dispersos no cotidiano, reencontro, em minhas anotações de campo, alguns dos atores do projeto Bahia Azul. 
Assim como eu e outros tantos colegas-bolsistas de pesquisa, naquele momento, eles também pareciam ansiosos para entender sua própria trajetória acadêmica. Minhas interlocutoras, algumas delas recém-formadas e ainda graduandas, como era o caso das profissionais e estudantes de nutrição responsáveis pela antropometria, também queriam conhecer os resultados ou mesmo a importância de sua pesquisa. Se meu diário e minhas anotações de campo produziam narrativas, suas anotações e questionários produziam números. No final do processo, de maneira muito similar, todos nós parecíamos indagar sobre as informações na forma de texto, buscando registrar, fixar ou retomar a ordem das coisas.

\begin{abstract}
Aí você vai ver até o resultado do que você fez, porque como Ataimá, Irlime ${ }^{3}$ estava falando, a gente foi a campo, coletou dados. E daí, e o resultado disso? E aquela criança que, olhando, pesando, medindo, eu vi que está desnutrida, o que vai ser feito daquela criança? Como, estatisticamente, ela vai se colocar em relação às outras crianças que também foram medidas, também foram avaliadas, entendeu? Qual o resultado disso? O que é que a gente vai fazer com esses dados? Qual a incidência de crianças, qual o número? Qual a prevalência de sempre... qual a prevalência de crianças desnutridas naquela comunidade que a gente mediu, pesou e avaliou? Qual o resultado disso? Para que isso vai nos servir? Como é que a gente vai poder agir, interferir na desnutrição daquela criança? Então, foi isso que achei fantástico, quando a gente resolveu trabalhar só com antropometria. Depois você vai avaliar essa antropometria, avaliar esses dados coletados, e depois alguma interferência vai ser feita, entendeu? Alguma atitude vai ser tomada, e você vai poder participar daquilo, avaliar... . Você, como nutricionista, como acadêmico também de nutrição, vai poder dizer: "Não, isso aqui não está bom". Vai poder opinar porque é a sua área, entendeu?

(Entrevista com a equipe da antropometria)
\end{abstract}

\title{
Ações conectadas na produção de dados epidemiológicos - ênfase na rede de mediação
}

Durante meu trabalho de acompanhamento e análise da situação de campo, estabeleci uma questão básica: nas interações comunicativas e dialógicas, em práticas de investigação epidemiológica, que atores se articulavam para produzir textos de saúde? Essa indagação encontrava-se diretamente vinculada a minha experiência etnográfica de tentar traduzir uma rede de comunicação cultural na produção de dados epidemiológicos. Em muitos momentos, me percebi na posição do estranho imerso em outros códigos e textos culturais, e quase tudo a meu redor se apresentava de modo singular: a disposição dos computadores, das cadeiras, dos agentes, as análises, as conversas triviais, as interações entre os diferentes níveis da pesquisa, as anotações, as caixas, os papéis, os rabiscos, as discussões, enfim, uma rotina que me era até então distante e praticamente desconhecida.

Entretanto, de acordo com uma tradição interpretativa de textos etnográficos, que busca combinar distância e proximidade diante de uma cultura estranha (Bibeau, Corin, 1995; Geertz, 2001), foi possível dialogar com os atores-pesquisadores sem perder de vista as respectivas trajetórias culturais e os usos de linguagem. Devido a meu 'excedente de visão'4 (Bakhtin, 1997) diante do outro - pesquisador, técnico, informante -, pude identificar uma rede de comunicação cultural na produção de dados epidemiológicos, ou, mais especificamente, uma mobilização de atores (humanos e não humanos), de repertórios e signos na produção de dados sobre saúde-doença. 
Durante minhas visitas às áreas investigadas pelo projeto Bahia Azul, diversos aspectos foram registrados nos encontros de entrevistadoras de campo e informantes, extrapolando as questões previamente estabelecidas como roteiro de investigação epidemiológica. As visitas às crianças do projeto ocorriam basicamente duas vezes na semana, em dias alternados, orientadas por ficha-padrão de seguimento de caso, anotando-se as respostas sobre diarréia (tipo de fezes), apetite, ingestão de medicamentos, ocorrência de adoecimento, febre, tosse, mudança nos hábitos alimentares etc. Paralelamente, seguindo ficha de avaliação, as entrevistadoras deviam registrar alguns aspectos observados durante a visita, por exemplo, se a criança estava descalça ou nua, se comia no chão, se havia alguma ave em casa etc. As assertivas eram listadas uma abaixo da outra, em formulário de leitura pouco agradável devido à grande extensão e problemas de diagramação. Essa verificação era difícil, dadas as contingências do contexto de investigação, ou seja, a rotina das famílias acompanhadas.

Durante as visitas, narrativas, histórias, casos sobre os hábitos de crianças e adultos iam-se misturando ao roteiro de investigação. Cada preenchimento de questionário significava uma atualização dialógica - cada número ou, melhor, cada 'sim' (1), 'não' (2), 'não sabe', 'não responde' (99 NS/NR), e, em caso de sim, um 'por quê?' - no interior de um diálogo, em cadeia de comunicação na qual os interlocutores participavam ativamente da interação discursiva. Na prática da investigação, de fato, os enunciados pareciam ter endereço, antecipavam a resposta (Bakhtin, 1998, 1999), ainda que estivessem em região fronteiriça de cooperação e resistência.

Entrev. 1: Eu tenho crianças que têm problema de prisão de ventre; não é a mãe que me dá informação ... eu coloco lá 99 quando é tia, por exemplo. Eu tenho uma que é tia, outro dia me deu uma informação. Eu perguntei: "O cocozinho?" "Não, fez uma vez". Eu digo: "Marquinha!" "Não, uma vez o dia todo". Eu sei que não é verdade. Eu coloco 99 por quê? Porque ela não faz todo dia. Aí a mãe diz: "Não; tal dia fez, tal dia não fez, tal dia fez". Mas a tia não sabe que ela não fez todo dia, ou uma vez por dia, ou faz uma vez por dia - não é verdade .... . Na minha área ... que a mãe que fica dentro e nunca sabe quantas vezes o menino faz cocô, nunca [enfatiza], eu já pergunto assim: "E aí, Aparecida? Hoje, quantas vezes Henri...?"

Entrev. 2: Eu não sei...acho que não...

Entrev. 1: "Ah, Amistifa, eu não tenho tempo de observar não, eu não sei não.' "Sabe não, não é, minha filha?"...

Entrev. 3: Aí sim...

Entrev. 1: A 99 nunca sabe. Eu fico impressionada: não trabalha, não faz nada... ela nunca sabe quantas vezes...

(Entrevista com entrevistadoras de campo)

Nos contextos comunicativos de produção de inscrições (anotações e números nos questionários e fichas), os indicadores/signos biológicos estavam conectados/mediados por signos culturais - um deslocamento possível através dos textos de cultura (verbais e não verbais), dos instrumentos (folhas de anotação), das técnicas de escrita disponíveis e das convenções sociais (o que se deveria anotar, como anotar, onde anotar, por que anotar etc.). Dessa forma, as maneiras/modalidades como se processavam perguntas e respostas não ocorriam no vazio. As técnicas de registro, os usos e situações sociais dos enunciados 
restringiam possível confusão ou deriva de sentido. As anotações sobre diarréia e doença ou eram restringidas pelos limites/usos impostos pela própria pesquisa - as entrevistadoras haviam sido treinadas e continuamente eram supervisionadas - ou mesmo pelos hábitos reconhecidos socialmente. Vale notar, entretanto, que nos momentos ou encontros dialógicos ocorria a 'interseção' de trajetórias culturais. Nas anotações sobre tosse, diarréia e doença, podia-se encontrar situação que indicava normalidade para o(a) informante, porém doença para a entrevistadora. Essas trajetórias culturais ficavam mais contundentes no decorrer do preenchimento do questionário.

Para uma mãe, por exemplo, seria problemático lembrar quantas vezes a criança fizera cocô; para outra, a pergunta "como está o...(nome da criança)?" poderia remeter à dificuldade de também indicar a quantidade de evacuações. A questão referente a 'cocô mole' ou 'fezes líquidas', justificando a presença da diarréia, implicava sentidos diversos. A pergunta "teve diarréia?" parecia associar-se a uma resposta já aguardada pela entrevistadora no momento de fazer a segunda pergunta: "líquidas?". Em relação às possibilidades das respostas entre 'mole' e 'líquidas', de modo geral as entrevistadoras afirmavam que 'elas', as mães/informantes, associavam diarréia a fezes líquidas. As amolecidas não eram, na explicação de uma de minhas interlocutoras, "motivo de diarréia".

É bem verdade que, numa visita, ouvi a entrevistadora perguntar sobre fezes 'moles' ou 'líquidas' (às vezes, antes de perguntar sobre diarréia, indo direto ao freqüente "e o cocozinho?"). Em um desses casos, saiu "pastosas/líquidas". A entrevistadora, então, pediu explicação, insistindo para a mãe escolher "uma ou outra". As brincadeiras, esforço da entrevistadora para estimular a lembrança da mãe, eram freqüentes, sempre oferecendo a alternativa "se você não lembrar, tudo bem". Ouvia também: "a tosse continua?", "apetite continua...!" (afirmativamente), "peito não?". As frases, às vezes interrompidas, parecendo aguardar uma resposta já esperada, eram seguidas por expressões faciais ou interjeições comprovando uma expectativa ou um código reconhecido simultaneamente pela entrevistadora e informante.

Vale, então, enfatizar o fato de que a inscrição de signos biológicos - tosse, febre, gripe, diarréia - no questionário se objetivava por processo dinâmico de mediação em que o ato de responder adquiria sentido narrativo, no qual entrava em cena o cotidiano familiar e seu entorno, nesse caso incluindo a própria posição ocupada pela entrevistadora. Esse sentido narrativo, na perspectiva de trazer para a ação discursiva o que foi ou pode ter sido perdido, ou o que está distante, encontra-se em consonância com uma das características da narrativa destacadas por Bruner (1997), ou seja, "ela se especializa em forjar ligações entre o excepcional e o comum" (p.48). Por outro lado, Gergen (1997, p.247) enfatiza que as narrativas obtêm utilidade primariamente em trocas/intercâmbios sociais, importantes para manter a inteligibilidade e coerência da vida social.

Devo ressaltar que os próprios artefatos, instrumentos, técnicas, objetos, materiais, coisas da natureza não apenas se deslocam e se transformam por meio das narrativas, mas também produzem, mobilizam e fazem circular essas mesmas ações discursivas. Nesse sentido, a própria narrativa é constitutiva de uma rede híbrida em que se conectam e se produzem história, sociedade, indústria, política, ciência, natureza, microorganismos etc.

Em relação a essa narrativa familiar posicionava-se a entrevistadora, tornando-se parte constitutiva de um momento dialógico ou, melhor, dessa rede de participação híbrida. 
Assim, retroceder nas questões, reconhecendo alguns hábitos das crianças, dinâmica familiar e materiais distintos era uma das estratégias disponíveis para que se alcançasse a inscrição pretendida diante dos limites das respostas para os episódios de diarréia, ou seja, diante do suposto esquecimento das informantes. Na dinâmica da produção de dados, considerando os ruídos ou interferências de traduções/interpretações, assim como as resistências das informantes e das técnicas disponíveis de registro, a entrevista tornava-se, portanto, um espaço de negociação e de posicionamentos, pelo qual se buscava atingir um efeito prático: a circulação dos dados epidemiológicos.

\footnotetext{
É, e tem o horário em questão. Tem crianças que têm rotina. Por exemplo: "Ela faz todos os dias", "Ela obra uma vez ao dia, é religioso". Assim como tem adultos, tem crianças... Então existe, por exemplo, aquela mãe [em que] você percebe um certo cansaço, um desinteresse: "Ah, tudo igual, tudo normal". Quando você começa [a] retroceder... Por exemplo, hoje é quarta. Eu pergunto em relação à terça, segunda: "Mãe, e ontem, ela fez quanto?" Se você perguntar assim... Porque é a maneira como você questiona: "Ela continua fazendo... obrando uma vez ao dia?" "Ah, continua". Mas se você perguntar "Mãe, ontem ela obrou uma vez só?" ou "Quantas vezes ela obrou?", "Ah, ontem, menina, ontem ela comeu muita besteira" ... Normalmente [no] final de semana a criança que tem tendência a ter problemas de desarranjo, diarréia...: "Ah, ontem ela comeu muito salgadinho; ela obrou quatro vezes"... Você pode ver: no geral, na ficha, a criança normalmente só faz uma ou duas vezes, [mas] no domingo ela fez quatro vezes. Então, é [o caso] de você retroceder cada dia. De forma que tem que ter cuidado, porque se você pergunta "continua fazendo uma vez?", é muito cômodo e confortável para quem pergunta e para quem responde. Mas é difícil, porque, por exemplo, uma criança numa casa que tem avó, tem tia, vários tomam conta. Isso em relação a uma criança pequena, que dependa... Tudo bem que aqui é de zero a três anos, normalmente são todos pequenos, mas uma criança menor, ... é duvidoso a quantidade de obrar, porque ela pode ter feito, um limpou, outro saiu e não está no momento... Ela vai dizer o que viu, tanto é que a ficha está bastante clara: o que ela observou, quer dizer, o que a mãe presenciou ou quem no momento estava ...

(Entrevista com uma revisora de questionários)
}

Diante das contingências da própria trajetória de produção de dados, a entrevistadora transitava, então, entre o desinteresse da informante, a necessidade da informação e as estratégias de investigação que se mobilizavam no decorrer da ação interativa. Por exemplo, nos casos de substituição de entrevistadora de campo, produzindo-se ruídos na comunicação entre pesquisa e população, as estratégias ou recursos mobilizados para que se estabelecesse nova relação de confiança e credibilidade variavam segundo a própria disponibilidade de informação e de interesse para os agentes envolvidos. Nessa direção, a entrevistadora, ao negociar com uma informante a permanência da criança na coorte, produzia seus próprios argumentos sobre a necessidade da pesquisa. Se, para a mãe, a relação entre pobreza e descuido com as crianças era incoerente, sendo a pesquisa mais próxima da realidade do outro, do que 'precisa mais', da 'invasão de baixo', para a entrevistadora, buscando dar continuidade à produção de dados, acomodando os conflitos e ruídos de comunicação, tornava-se necessário utilizar os recursos e materiais disponíveis no momento, por exemplo, as informações disseminadas pela televisão sobre a qualidade da água como problema que atravessa todas as classes sociais; portanto, estendendo a preocupação da pesquisa para além da higiene, do andar descalço ou 'de pé na lama'. Por outro lado, a entrevistadora 
utilizava a possibilidade da consulta médica para destacar um dos aspectos positivos da pesquisa, ainda que tivesse de negociar a própria credibilidade do projeto, devido à demora no resultado dos exames do parasitológico e tratamento das crianças infectadas.

\begin{abstract}
“O coordenador esteve lá...". Então falei: “O coordenador?" "É, esteve aqui, disse que... nós somos pobres mesmo, mas nossas crianças são bem cuidadas, não andam descalças e não vivem de diarréia"... Elas usaram termos de que é só quem trabalha aqui que tem acesso a esse tipo de situação; elas não iam saber de uma vizinha, então eu falei: "Não, ao contrário; se fosse assim, nós não estudaríamos a Barra". Até eu falei uma mentirinha: "Nem encontraríamos diarréia crônica na Barra, um bairro de classe A. O interesse não é só a área pobre; pesquisa estuda todas as classes sociais, A, B e C, entendeu? E ninguém está dizendo que as crianças daqui andam descalças...". Porque tem tanta criança que precisa, criança ali, ó, essa criança na invasão embaixo... Quer dizer, lá também é invasão, mas elas não consideram; a invasão é lá embaixo, entendeu? "A invasão lá embaixo" é o final de linha, ali, Santa Mônica, Pero Vaz, que é o que eu faço também [aumenta a voz, respondendo já a uma tentativa de indagação]... "Vive descalço, no pé da lama; aqui não" ... Eu falei: "Não, senhora, olhe bem, a questão, por exemplo, da diarréia; não é só uma criança que anda descalça, de pé na lama .... . A importância desse estudo também é a água, a água que nós bebemos hoje..." . Coincidentemente na época teve uma reportagem no Fantástico falando dessa questão da água, que mesmo com os filtros, com todos os cuidados, a gente ainda corre risco de contaminação. Então eu falei: "Até água mineral hoje é duvidosa. É esse o estudo, o intuito dessa pesquisa é isso, é estudar a questão da diarréia, entendeu? Não só higiene, a questão do saneamento, da água, também são muito importantes nesse estudo. Sua filha tem direito à consulta, entendeu?" ... "Já foi no médico?" "Não foi" ... "Ela ainda tem direito à consulta, entendeu?" Ela falou: "É, fez exame de fezes, nunca mais trouxe". É porque a reclamação foi geral, pela demora do resultado ... "Os exames - eu falei -, eu vou no escritório quarta-feira; se tiver algum lote pronto, alguma coisa, eu já trago para a senhora. E aí a senhora vai continuar no projeto?" "É, você passa aqui e eu vou pensar, né?"... Então é isso.
\end{abstract}

(Entrevista com uma revisora de questionários)

A diversidade de demandas das populações envolvidas no programa Bahia Azul mobilizava outros interesses das comunidades para além da intervenção biomédica. As entrevistadoras de campo se deparavam com expectativas que abrangiam a própria resolubilidade do programa como possibilidade concreta de melhoria das condições ambientais e de vida da população. Durante meu percurso em campo, enquanto as mazelas de uma área iam sendo apontadas, ouvia da entrevistadora respostas taxativas sobre os benefícios e retorno do programa: "Não há benefício, não retornamos nada para as famílias". Dessa maneira, através de minhas interlocutoras, outros pontos de vista eram disponibilizados; por exemplo, quando dizia às famílias que os benefícios viriam depois, devagar, uma entrevistadora de campo observava: "Mas eles já estão tão desacreditados! No início me diziam 'isso [o Bahia Azul] nunca vai chegar aqui'".

Entrev. 1: Só que eles também perguntam se o projeto Bahia Azul realmente vai passar por lá, se vai asfaltar as ruas, se vai acabar com as redes de... com as valas de esgoto que têm nas casas, nas portas... Porque mesmo lá na minha área, na $677 .$. Você não teve a oportunidade de ir comigo, não foi? Mas parece uma piscina, é assim na porta da pessoa. Então tem aquelas pontezinhas feitas de madeira, para passar e ter acesso à casa, para poder entrar na casa, e passa por cima de uma vala de esgoto ... O canal de lá está fechado... [confusão]. 
Entrev. 2: Então eles perguntam também: “Com certeza, moça, o Bahia Azul vai passar por aqui?". E no início eles achavam que a pesquisa era para tirar as casas deles da invasão...

Entrev. 1: Mas perguntam muito... [risos].

Entrev. 2: Mas ficavam perguntando: "Vão tomar minha casa? E vão me mandar para onde?"

Entrev. 1: "Moça, é da Coelba? Da Embasa?" [risos].

Entrev. 2: "É da Embasa? Da Coelba? Vai cortar minha luz?” “Ói, aqui é gato. Você não vai dizer lá que é gato não, né?"

Entrev. 3: Valeu uma observação assim: "Peraí, peraí, peraí, que eu tenho um bocado de filha" ... "Não é, não" - aí explico tudo direitinho... "Ah, sim..."

Entrev. 2: [conversas paralelas] E outros que chamam: "Como é que faço para colocar meu filho nesse projeto, fala com quem?" Aí você tem que explicar que antes foi feito um censo, fez um sorteio e tal, tem que explicar tudo direitinho.

(Entrevista com entrevistadoras de campo)

Por conseguinte, ainda que houvesse alguma tendencialidade interpretativa no contexto da investigação científica, ou seja, em direção a repertórios argumentativos mais gerais, de base epidemiológica, cada nova atualização ou momento da pesquisa podia significar possível abertura para outros sentidos e interesses em foco. Esse jogo conversacional na arena transcientífica (Knorr-Cetina, 1983), que inclui diversas trajetórias de usos e hábitos culturais, desafia a própria efetividade de entendimento mútuo.

Entrev. 1: Tem mães que acham muito importante esse trabalho que a gente faz, inclusive elas acham que a gente sabe tudo, sabe mais [risos das colegas]. Exatamente; eu acho que nós somos mal preparadas para esse tipo de trabalho de saúde.

Entrev. 2: Pensam logo que a gente é médica...

Entrev. 1: Pois é.

Entrev. 3: Isso.

Entrev. 2: ...pergunta se tem aparelho para tirar a pressão [confusão de vozes]...

Entrev. 3: ....[confusão] Fala assim...

[Duas vozes simultaneamente]: “Já vem a médica, já vem a médica de fulano...” [confusão].

Entrev. 2: ...ou a enfermeira. E às vezes a criança está com determinado problema, uma diarréia, uma coisa assim, fica perguntando que remédio dar, entendeu? Fico sem saber o que responder...[confusão de vozes, todas falam ao mesmo tempo].

(Entrevista com entrevistadoras de campo)

Vale ressaltar que a idéia de tendencialidade se fundamenta em leitura do semioticista americano Charles Peirce (1999). Nessa perspectiva, segundo Lúcia Santaella (2000), podemos reconhecer a ação sígnica como "crescimento contínuo e tendencialidade" (p.74). O signo tende para o futuro, é incompleto, sendo potencialmente infinito. O potencialmente, portanto, deve ser compreendido a partir de um 'terceiro', já que no processo de tradução ou mediação sígnica ocorre certa tendência/determinação do sentido em relação às convenções e hábitos.

No entanto, ratifico que a atividade de produção de textos científicos gera e faz circularem outras estratégias de coleta e análise de dados, bem como atualizações de sentidos. Essa 
perspectiva parte da premissa de que, na prática de produção epidemiológica, os agentes se encontram engajados circunstancialmente, delineando-se contextos relacionais de cooperação e/ou resistência (Pickering, 1999). Esses contextos constituem o que designei como momentos dialógicos implicados por um terceiro - pelo reconhecimento de hábitos (sociais, científicos e naturais) ou regras metodológicas (Silva, 2003).

Entrev. 1: Pois é, mas o problema... [confusão]

Entrev. 2: “...então dê bastante banana para prender”.

Entrev. 1: O problema todo é esse, nosso problema todo é esse, nós somos só...

Entrev. 2: entrevistadoras, só entrevistadoras.

Entrev. 1: A gente não pode entrar na intimidade...

Entrev. 2 [simultaneamente]: Dar uma orientação mais...

Entrev. 1: ...na vida deles, senão perde o valor da pesquisa para o projeto. Se a gente começar a dizer que tem que fazer isso, fazer aquilo, no final do projeto acabou, não valeu a pesquisa. Valeu, mas nós forçamos a barra, induzimos a tratamento, e não é isso a base da pesquisa, no meu modo de ver.

Entrev. 3: É...Quebrado o gelo, hoje a gente vê que é muito pouco, a gente oferece muito pouco. Pela situação que vivenciamos, oferecemos muito pouco. Eu me preocupo: depois no final do Bahia Azul, o que vai ser daquelas crianças?

Entrev.1: Sabe o que eu discordo de você? Você me desculpa, mas é que... a culpa não é nem do projeto, não é nem minha, nem é sua. Porque a gente passa a parte emocional, mas na verdade pesquisa é isso, a gente não pode se envolver de uma maneira emocional. Já pensou se a gente fizer isso?

Entrev. 1: Conclusão: o que ocorre é que acabamos nos envolvendo emocionalmente, mas também temos que separar, somos obrigadas a fazer isso.

Entrev.3: ...não; a gente separa, a gente acaba tendo que separar.

Entrev. 1:...o médico, compreende, o enfermeiro... Quantas vezes dizemos assim: 'Ô, médico é tão frio!"? Você já pensou...

(Entrevista com entrevistadoras de campo)

Devo ressaltar que, no cotidiano de investigação, as entrevistadoras davam lugar a outros agentes científicos de mais credibilidade na produção e tradução de dados epidemiológicos. Em processo de mediação contínua, a partir dos acordos e contratos estabelecidos, os momentos particularizados mais imediatos da produção científica de certa forma eram deslocados e distanciados, buscando-se produzir textos mais amplos, gerais e ordenados. Por exemplo, no trabalho de crítica - atividade de revisão de questionários e fichas do seguimento - era possível encontrar situação de simultâneos distanciamento e aproximação, em que os 'tradutores' de dados se esforçavam para estabelecer novas conexões e analogias entre uma inscrição ou signo particular, os objetos/discursos ausentes e os efeitos práticos de uso científico. Nesses momentos, buscava-se assegurar uma ordem ou coerência para o que se apresentava de modo confuso, ambíguo ou incerto diante dos objetos e objetivos da pesquisa.

O que eu percebi foi isso. Eu perguntava como está exatamente no texto: "Suspendeu a mamadeira?" E uma mãe falou: "Não, ele não toma mais mingau". Então eu pude perceber a resposta correta, pela forma como ela respondeu. Então falei: "Não, mingau..." E ela: "Não, 
mingau eu dou no pratinho, faço mingau mais...". Então falei: "Não é só o leite, o mingau. Ele tomou um suco, uma água na mamadeira?” “Ah, ele toma”. Então ela não suspendeu; ele continua usando a mamadeira, entendeu? ... Então o que eu percebo é o seguinte: você tem de deixar bem claro que não é o mingau que a criança toma, o leite, porque a pessoa associa a mamadeira ao leite ou ao mingau. Não é essa a questão, o que se está querendo saber é... Isso foi acontecendo no decorrer dessa crítica, por uma curiosidade da minha parte ... Falei com Cronos: "Você está querendo saber realmente o quê? É a higiene da mamadeira ou o líquido? Se a criança tomou?" Ele falou: "Não, independente do líquido, eu quero saber os cuidados que essa pessoa tem com a mamadeira". Aí já é outra visão, entendeu?

(Entrevista com uma revisora de questionários)

A velha questão da torneira... Não era a torneira. As pessoas ficavam, eu acho, sem saber até como colocar essa questão. Porque [se trata do] ponto de água, entendeu? Então [em vez de] quantas torneiras a pessoa tem em casa, para mim, se o treinamento fosse claro, seria: o acesso à água [é] dentro da casa dela ou fora do domicílio dela? É um ponto de água, ou chafariz; se ela usa água do charafiz, se toma banho do chafariz, se ela usa água da vizinha, entendeu? Porque ... o que é que tem torneira? Uma pia no banheiro, uma pia na cozinha, uma pia na lavanderia, uma no jardim. A gente supõe isso, mas aí foi com torneira. Era todo ponto de água: um chuveiro, um filtro de parede. Que você tem a água, você tem acesso à água, você bebe, ingere a água, e isso está sendo estudado também. Quer dizer, nós começamos a corrigir quantidade de torneira, e não pontos de água.

(Entrevista com uma revisora de questionários)

Vale também enfatizar que as situações de conflito não eram exclusivas das entrevistadoras de campo, já que eram vividas também no cotidiano de outros atores, por exemplo, no grupo da antropometria: estudantes de nutrição e nutricionistas, responsáveis pelas medições das crianças de zero a três anos como indicadores do estado nutricional. De seis em seis meses, a equipe voltava às áreas do projeto para medir e pesar as crianças - registrar comprimento (Comp), comprimento do braço (CB) e peso.

É interessante notar que as nutricionistas envolvidas diretamente na antropometria se haviam formado há dois anos. Na prática de investigação, mesmo como coordenadoras de campo, também compartilhavam com as estudantes um roteiro de atividades - medir, pesar, carregar balança, comparar margem de erro, não podendo passar de 0,5 para Comp, e 0,2 para CB (enquanto uma media, outra observava). Todas demonstravam relação de proximidade, até com o motorista ou com as entrevistadoras de campo. Nesse contexto relacional, demarcava-se a diferença/distância de outros pesquisadores, às vezes taxados de 'pesquisadores de gabinete'.

Na trajetória de acomodação de dados ou produção de metalinguagem científica, enquanto outros pesquisadores respondiam a uma demanda crescente de informação, a partir de seu próprio engajamento na rede de negociação de interesses (acadêmicos, econômicos e políticos), investindo em credibilidade, as pesquisadoras/nutricionistas deviam rever e administrar possíveis problemas, falhas ou ruídos de significação dos dados. No esforço de acomodar uma situação de resistência/conflito na interpretação dos dados, através de analogias, buscavam reconhecer um mundo possível para o estabelecimento de ordem/regras; por exemplo, em se tratando da impossibilidade de crescimento negativo. 
Nutri. 1: Ele apontou o problema... alguns de nós tínhamos detectado no campo mesmo, na pesquisa de campo...

Entrevistador: Por exemplo?

Nutri. 1: Por exemplo, uma criança que na primeira antropometria estava com $78 \mathrm{~cm}$, na segunda fase tinha $75 \mathrm{~cm}, 76$. Quer dizer, uma criança não pode encolher, não é?

Nutri. 2 : Ela não entra na medição...

Nutri. 1: Ela cresce, ela pode crescer pouquinho, pode crescer muito, pode crescer médio, mas encolher ela não encolhe, certo? Então esse problema nós conseguimos detectar em campo, porque saímos para a segunda fase da antropometria com...

Nutri. 3: com as medidas da primeira.

Nutri. 1: Por exemplo, há casos que ele detectou de crescimento zero.

Nutri. 4: Isso não pode acontecer.

Nutri. 1: Não pode acontecer um negócio desse. A criança, por mais que ela... Ela pode ter tido vários episódios de diarréia, durante não sei quantos meses...

(Entrevista com equipe da antropometria)

No confronto de distintos repertórios e hábitos culturais, a partir de uma demanda de produção de dados científicos, as pesquisadoras responsáveis pela antropometria também se utilizavam de uma trajetória específica para acomodar uma situação de resistência. Nas áreas saneadas, em comparação às não saneadas do programa Bahia Azul, as pesquisadoras enfatizavam uma dificuldade contínua na obtenção de dados. As desistências e recusas eram justificadas pelas mães como uma não-necessidade de fazer parte da pesquisa: "Por que está avaliando meu filho, se tem crianças que precisam?"; "Meu filho não gosta"; "Eu tenho plano de saúde, meu filho tem pediatra, pesou essa semana, mediu essa semana". Nesse jogo conversacional, em que está implicado o próprio reconhecimento social de um grupo, busca-se definir as posições mediante o uso de habilidades, palavras/termos, justificados como técnicas - 'competência' vinculada a uma trajetória de aquisição de conhecimento, retirando-se, entretanto, seu sentido comum, ordinário, do cotidiano.

Nutri. 1: Quando elas próprias não querem fazer a medida, quando a criança está chorando, enjoadinha, o corpo todo está doente, com febre. Como uma mãe, uma vez, disse: "Não, deixe que eu meço o braço dele". Então Harva disse: "A senhora pode até medir, mas primeiro a senhora vai ter que localizar o acrômeo, o iométrono [Rana cai na gargalhada]. O acrômeo ainda pode ser, que é mais fácil, mas o iométrono é um pouco mais difícil. Depois vai ter que tirar o ponto médio para poder calcular CB". E ela: "Não, não; faça você mesma". Então, tem que usar esses termos, assim...

Nutri. 2: ...tão difíceis...

Nutri. 3: Que têm toda uma técnica, né?

Nutri. 1: Para poder intimidar a mãe e ela se conscientizar de que ela não tem...

Nutri. 3: ... capacidade...

Nutri. 1: É, aquele conhecimento para fazer aquela medição.

Nutri. 4: Porque, na realidade, você faz a antropometria, você tem a técnica...

Nutri. 3: ... toda uma técnica...

Nutri. 4: ... toda uma técnica. Foi padronizado, houve um treinamento prévio; então tem uma padronização. Pôxa, todo mundo pensa que é fácil, mas não é fácil, entendeu? Você tem 
o padrão, você tem que dominar a técnica. Se dominando a técnica você corre o risco de errar, imagina uma pessoa que não domina. Então eu coloquei os termos técnicos mesmo, entendeu?

(Entrevista com equipe da antropometria)

Dando prosseguimento à rede de circulação do dado, pude registrar o esforço de 'acomodação' de taxas e freqüências a significados possíveis para episódios de diarréia, quando um determinado valor/signo representava uma inconsistência no mundo prático: com um notebook, e auxílio de um estatístico (importante 'peça' na produção, leitura ou tradução de inscrições numéricas), um doutorando em epidemiologia se inquietava diante dos números produzidos, de dúvidas e equívocos, que eram traduzidos/confirmados através de exclamações do tipo "imagina se é possível, a criança derrete!".

Conforme destacado por Latour e Woolgar (1997), o investimento na formação acadêmica significa, ao mesmo tempo, importante investimento para a instituição, como possibilidade de garantir informação no futuro (novas publicações e relatórios), bem como estabilidade de financiamentos. Portanto, na resolução de um conflito, devem ser levados em consideração 'boas' tabelas, 'bons' instrumentos/software e domínio de um discurso para a (re)constituição de 'boas' justificativas.

\footnotetext{
Mas as pessoas evidentemente não conseguiram, com instrumentos apenas, com instrumentos que utilizamos, perceber esse tipo específico de problema, que foi descoberto apenas quando, uma vez terminada uma parte da digitação dos dados, foi feita a limpeza, e fui ver um certo tipo de consistência e percebi que esse achado não era possível, que não era possível ter tão pouca diarréia numa área que tem mais desse tipo de fenômeno e também tem mais de parasitas, tem mais desnutrição. Então esses dados não batiam mesmo, e foi assim que descobrimos.
}

(Entrevista com epidemiologista responsável por uma das pesquisas do projeto)

Nessa direção, a tradução dos dados depende também das posições estratégicas de atores específicos na rede, capazes de modificar ou retomar o fluxo de informação científica. Vale ressaltar que Latour e Woolgar (1997, p.239) utilizam a perspectiva de campo científico de Bourdieu (1983), como lugar de luta de interesses, mas simultaneamente a idéia de campo agonístico, que se refere mais a afirmações do que à idéia de organização. As trajetórias individuais, portanto, estão localizadas, o que significa dizer que as estratégias também estão mobilizadas a partir das 'forças do campo'. Na análise de uma posição ocupada por um pesquisador, deve-se considerar sua trajetória de carreira, a situação de uma disciplina, os recursos que o cientista detém e as vantagens que essa posição pode oferecer (Latour, Woolgar, 1997, p.240). Um doutorando em epidemiologia, por exemplo, não poderia esquecer que sua carreira ou formação acadêmica depende, de certa forma, das 'boas' e 'novas' informações geradas pelo projeto Bahia Azul.

Latour (2000, p.112) também chama o instrumento de 'dispositivo de inscrição', fazendo referência a "qualquer estrutura (sejam quais forem seu tamanho, sua natureza e seu custo) que possibilite uma exposição visual de qualquer tipo num texto científico". No contexto de produção de textos epidemiológicos, o computador é o instrumento para o qual se direcionam os diferentes profissionais. Através de um software específico, o Epi-Info, por exemplo, as medidas e respostas de questionários são traduzidas por variáveis em uma estrutura de linguagem computacional. Os digitadores, incluindo bolsistas e outros 
pesquisadores geralmente no início de carreira, preenchem esse campo de proposições genericamente denominado máscara - seguindo um repertório de opções preestabelecido. As sucessivas traduções estão restringidas pela estrutura do programa, ainda que aos principais pesquisadores caibam a interpretação, inclusão ou supressão de novos signos/ respostas/valores.

Diante dessa rede de produção (e transformação) dos dados, é interessante notar que as tabelas e gráficos pareciam traduzir, por si, um mundo aparentemente disperso, confuso e distante. As muitas inscrições, os números sistematicamente organizados (os $\mathrm{N}$ da amostra, número de perdas, distribuição de freqüências), mediados pelos distintos atores, que incluem os instrumentos ou dispositivos de inscrição, chegavam às reuniões e relatórios traduzidos por confiabilidade, generalidade, significância, na indicação e promessa de novas informações e perspectivas analíticas - desdobramentos de um trabalho para futuras publicações.

Foi através desse deslocamento de atores na cadeia de transformação científica, a partir do que Latour (1999b) explicita como referência circulante, que pude visualizar meu próprio trabalho etnográfico. Nesse processo de transformação, em cada estádio ou movimento, perdem-se propriedades, elementos, para que outros sejam obtidos; ou seja, na cadeia de transformação reversível, se a produção científica perde em particularidade, materialidade e multiplicidade, em contrapartida ganha em produção de textos, calculação, padronização e circulação (p.70), podendo o leitor retornar ao local de origem dos fatos e às 'próprias coisas'.

Finalmente, gostaria de enfatizar que as expectativas na obtenção de respostas - de certa forma promessas que projetam um futuro, por exemplo, através de relatórios, congressos, dissertação e artigos - concretizaram-se (e se concretizam) apesar das restrições e dos limites do material etnográfico disponível, em condições concretas de existência. Minhas indagações (e possíveis respostas) não deixam de levar em consideração, portanto, as exigências de um campo de práticas e discursos - da Saúde Coletiva, no qual me posiciono como mais um interlocutor -, assim como as resistências e os conflitos que se fizeram presentes no processo de produção etnográfica.

\section{Conclusão: um giro narrativo}

No esforço de alcançar uma síntese narrativa, gostaria de retomar alguns aspectos destacados no processo de transformação de dados ou textos epidemiológicos. Conforme previsto, traduzi o processo de construção de dados científicos a partir de uma rede contínua de mediação. Assim, quando localizei essa rede de comunicação cultural, a partir dos objetos e agentes que se movimentavam no cotidiano de investigação epidemiológica, de certa forma acompanhei o desdobramento dos níveis de mediação. Esse recurso interpretativo trabalha com a perspectiva de que os diversos agentes (científicos e não científicos; humanos e não humanos) se movimentam como mediadores e mediados na produção de textos de saúde. Os momentos dialógicos implicados nessa produção significam, portanto, atividades de mediação ou atualização possível de sentidos da relação saúde/enfermidade/cuidado.

Nas atividades de campo, em que as entrevistadoras processavam os números e anotações nas fichas de seguimento, chamei a atenção para uma rede de ação em que se 
interconectavam signos biológicos/naturais e culturais. Dessa forma, localizei a própria entrevista como ato conversacional ou espaço de negociação e de posicionamentos, buscando-se produzir inscrições e signos interpretativos - a objetivação do dado, pela produção de inscrições, ocorria mediante o reconhecimento de uma narrativa familiar e de hábitos sociais, científicos e naturais.

Nos vários encontros dialógicos, em que entrevistadora e entrevistado(a) estavam engajados(as) temporariamente na produção do dado, caracterizei os distintos níveis de mediação a partir da mobilização ou deslocamento de signos e estratégias discursivas. Nessa perspectiva, os agentes humanos e não humanos (mediadores e mediados) que circularam no cotidiano de investigação epidemiológica eram participantes ativos na construção de teias narrativas ou, mais objetivamente, na construção de dados e informações científicos.

Acompanhando as ações conectadas dos distintos atores, incluindo a participação/ mediação dos computadores na atividade de calculação, padronização, generalização e circulação de informação e conhecimento científico, foi possível estabelecer um 'diálogo' entre natureza e cultura/sociedade. Em se tratando do processo de transformação de dados em informação científica, as anotações/respostas e inscrições (números, tabelas e gráficos) parecem envolver, simultaneamente, um trabalho de construção, descoberta e convenção científica (Latour, 1999b).

Nessa trajetória, diferentes estratégias também foram mobilizadas para acomodar as resistências e ambigüidades oriundas das relações entre os diversos atores. Cabe, então, destacar que nossos enunciados e inscrições são reconhecidos e objetivados por serem signos sociais e, portanto, se destinam a um público, estão investidos de historicidade, conformam hábitos, esforçam-se para traduzir uma 'linguagem' em outra, por exemplo, natureza em cultura, adquirem novas formas e qualidades, configuram e/ou alteram práticas culturais, sempre com o risco de produzir novos ruídos e interferências no processo de comunicação (Silva, 2003).

Quando afirmo que uma diversidade de agentes ou atores está situada/conectada no processo de produção de dados e informação científica, significa enfatizar, também, diferentes posições interativas. No entanto, ao mesmo tempo em que os atores (humanos e não humanos) estão posicionados uns em relação aos outros, produzindo mútuos e múltiplos efeitos, estão também mediados/constrangidos por normas de uso científico. A partir de uma metalinguagem epidemiológica, em posição de distanciamento na direção de repertórios formalizados e mais gerais, encontram-se aspectos 'definidores', ordenados, de produção de textos epidemiológicos, quando a circulação/demanda de informação científica faz demarcar um campo de oposições mais precisas: o que pode ser mensurado e o que não é mensurável; o que diz respeito à pesquisa quantitativa (dados quantitativos) e pesquisa qualitativa (dados qualitativos); o que se refere à objetividade e ao campo da subjetividade; o que é ciência e o que é política.

Finalmente, gostaria de lembrar que este artigo não teve a pretensão de desenvolver uma discussão epistemológica sobre o campo teórico-conceitual da epidemiologia, mas vislumbrar a ação cotidiana de um grupo de pesquisa, sobretudo de alguns atoresantagonistas que geralmente ficam na invisibilidade. Por outro lado, também não pretendi 
discutir os resultados finais do projeto Bahia Azul e suas repercussões em Salvador, mas apenas destacar que, entre os limites de um repertório formal e a prática diária de pesquisa, entre o publicado formalmente e o vivido cotidianamente, uma diversidade de atores, práticas e textos coexiste nos contextos abertos, dialógicos e confusos do dia-a-dia. Nessa perspectiva, a produção de sentidos no cotidiano vai além de sua metalinguagem científica. Reconheço que essa é, entre outros aspectos, uma das lacunas de meu trabalho, que pode, no entanto, servir, talvez, para outras pesquisas como registro histórico de um ensaio em estudos da ciência em Salvador, Bahia.

Para além dos dualismos tradicionais (sujeito/objeto, objetividade/subjetividade, natureza/cultura, realidade/construção, máquina/homem etc.), é possível pensar os vários agentes (e conceitos) de forma mais simétrica. Em se tratando das relações entre natureza e cultura/sociedade, talvez seja mais pertinente discutir a reciprocidade e os múltiplos efeitos dessas interações. Nessa perspectiva, são vários hábitos e interesses envolvidos entre os distintos atores, podendo ocorrer mútuas (e múltiplas) transformações. No final do processo, nem os humanos, nem as máquinas, nem a natureza são mais os mesmos.

\section{AGRADECIMENTOS}

Pela viabilização deste trabalho, gostaria de agradecer ao CNPq, que me concedeu bolsa de aperfeiçoamento científico; à colaboração, em diferentes momentos, dos colegas bolsistas Adilson Almeida, André Apenburg, André Stangl, Cristina Moreira, Dalton Barros, Lêda Xavier, Luciana Queiroz e Sílvia Regina de Souza Santos, assim como ao professor Naomar de Almeida Filho, por sua confiança e apoio em um jovem aprendiz.

\section{NOTAS}

${ }^{1}$ Este artigo decorre de minha participação como bolsista de aperfeiçoamento científico (CNPq), em 1998, no projeto de pesquisa Uma etnografia da epidemiologia: estudo das práticas científicas de duas investigações epidemiológicas em Salvador, BA - sob a coordenação geral do professor doutor Naomar de Almeida Filho, no Instituto de Saúde Coletiva, UFBA. No projeto original, houve também a participação dos professores Carmen Fontes Teixeira e Jairnilson Silva Paim. Cabe lembrar que até 1998 - quando eu acabara de concluir a graduação em psicologia e buscava iniciar o mestrado em Saúde Coletiva - havia uma modalidade de bolsa de pesquisa para recém-formados. Incentivado pelo prof. Naomar, passei a coordenar seus bolsistas de iniciação científica e a desenvolver meu próprio 'problema' de pesquisa. Este estudo etnográfico resultou em minha dissertação de mestrado, defendida em 2001, no Instituto de Saúde Coletiva da UFBA, e orientada pelo professor Naomar.

${ }^{2}$ A noção de repertório é aqui utilizada para designar a variabilidade de estratégias lingüísticas, situadas em contextos diversos, para dar sentido ao mundo; em outras palavras, o conjunto de conceitos, termos, vocabulários, descrições, figuras de linguagem etc., que demarca o campo de possibilidades de construções discursivas (Spink, Medrado, 1999; Spink, 2001).

${ }^{3}$ Todos os nomes de técnicos, pesquisadores e demais pessoas envolvidas nos projetos foram substituídos por pseudônimos.

${ }^{4}$ Sobre o acontecimento estético, Bakhtin (1997) enfatiza que o 'acabamento' vem do outro, em movimento que inclui identificação e retorno a si mesmo (ao lugar que ocupo com exclusividade). Sobre a relação autor/herói, Bakhtin (1997) sugere duas consciências que não coincidem. Nesse sentido, não podemos ficar alheios à posição que ocupamos no mundo, a um excedente de visão com relação ao outro. 


\section{REFERÊNCIAS}

BAKHTIN, Mikhail.

Speech genres \& other late essays. Austin:

University of Texas Press. 1999.

BAKHTIN, Mikhail.

The dialogic imagination. Austin: University of Texas Press. 1998.

BAKHTIN, Mikhail.

Estética da criação verbal. São Paulo: Martins Fontes. 1997.

BIBEAU, Gilles; CORIN, Ellen.

From submission to the text to interpretive violence. In: Bibeau, Gilles e Corin, Ellen (Ed.). Beyond textuality: ascetism an violence in anthropological interpretation. Berlim: Mouton de Gruyter. p.3-54. 1995.

BOURDIEU, Pierre.

O campo científico. In: Ortiz, R. (Org.). Pierre Bourdieu: sociologia. São Paulo: Ática. p.122155. 1983

BRUNER, Jerome.

Atos de significação. Porto Alegre: Artes Médicas. 1997.

CALLON, Michel.

Some elements of a sociology of translation: domestication of the scallops and the fishermen of St. Brieuc Bay. In: Biagioli, Mario (Ed.).

The science studies reader. New York: Routledge. p.67-83. 1999.

CLIFFORD, James.

A experiência etnográfica: antropologia e literatura no século XX. Rio de Janeiro: Ed. UFRJ. 1998.

ECO, Umberto.

Os limites da interpretação. São Paulo: Perspectiva. 1999.

GEERTZ, Clifford.

O saber local: novos ensaios em antropologia interpretativa. Petrópolis: Vozes. 2001.

GEERTZ, Clifford.

A interpretação das culturas. Rio de Janeiro: LTC. 1989.

GERGEN, Kenneth J.

Realities and relationships: soundings in social construction. Cambridge: Harvard University Press. 1997.

KNORR-CETINA, Karin.

Epistemic cultures: how the sciences make knowledge. Cambridge: Harvard University Press. 1999.

KNORR-CETINA, Karin

The ethnografic study of scientific work: towards a constructivist interpretation of science. In: Knorr-Cetina, K.; Mulkay, M. (Ed.). Science observed: perspectives on the social study of science. Beverly Hills: Sage. p.115-140. 1983.

LATOUR, Bruno.

Ciência em ação. São Paulo: Unesp. 2000.

LATOUR, Bruno.

One more turn after the social turn... In:

Biagioli, M. (Ed.). The science studies reader. New York: Routledge, p.276-289. 1999a.

LATOUR, Bruno.

Pandoras's hope: essays on the reality of sciences studies. Cambridge: Harvard University Press. 1999b.

LATOUR, Bruno.

On actor-network theory - a few clarifications. Soziale welt - zeitschrift für sozialwissenschaftliche forschung und praxis, Jahrgang, v.47, n.4, p.369-381. 1996.

LATOUR, Bruno.

Jamais fomos modernos. São Paulo: Editora 34. 1994.

LATOUR, Bruno; WOOLGAR, Steve. A vida de laboratório: a produção dos fatos científicos. Rio de Janeiro: Relume-Dumará. 1997.

LAW, John.

Notes on the theory of the actor network: ordering, strategy and heterogeneity. Centre for Science Studies, Lancaster University.Disponível em: http://www.comp.lancs.ac.uk/sociology/ papers/Law-Notes-on-ANT.pdf. Acesso em: 20 dez. 2007. 1992.

LÉVY, Pierre.

As tecnologias da inteligência. Rio de Janeiro: Editora 34. 2004.

MULKAY, Michael; POTTER, Jonathan;

YEARLEY, Steven.

Why an analysis of scientific discourse is needed. In: Knorr-Cetina, K. \& Mulkay, M. (Ed.). Science observed: perspectives on the social study of science. Beverly Hills: Sage. p.171-203. 1983.

PEIRCE, Charles Sanders.

Semiótica. São Paulo: Editora Perspectiva. 1999.

PICKERING, Andrew.

The mangle of practice: agency and emergence in the sociology of science. In: Biagioli, Mario (Ed.). The science studies reader. New York: Routledge. p.372-393. 1999.

RICOEUR, Paul.

Teoria da interpretação. Lisboa: Edições 70. 1996. 
SANTAELLA, Lúcia.

A teoria geral dos signos: como as linguagens significam as coisas. São Paulo: Editora Pioneira. 2000.

SILVA, Luis Augusto Vasconcelos.

Saúde e produção de sentidos no cotidiano: práticas de mediação e translingüística

bakhtiniana. Interface - Comuniação, Saúde, Educação, Botucatu, v.7, n.13, p.135-148. 2003.

SPINK, Mary Jane Paris.

Trópicos do discurso sobre risco: risco-aventura como metáfora na modernidade tardia.

Cadernos de Saúde Pública, Rio de Janeiro, v.17, n.6, p.1277-1311. 2001.

SPINK, Mary Jane Paris; MEDRADO, Benedito. Produção de sentidos no cotidiano: uma abordagem teórico-metodológica para análise das práticas discursivas. In: Spink, Mary Jane Paris (Org.). Práticas discursivas e produção de sentidos no cotidiano: aproximações teóricas e metodológicas. São Paulo: Cortez Editora. p.41-61. 1999.

\section{$\rightarrow \rightarrow \rightarrow<<<$}

